\title{
Digital Tomosynthesis
}

National Cancer Institute

\section{Source}

National Cancer Institute. Digital Tomosynthesis. NCI Thesaurus. Code C126695.

An imaging technique in which multiple X-rays of an object are take from a discrete

number of angles. These cross-sectional images are used to reconstruct 3-D images of the object being scanned. Tomosynthesis differs from computed tomography because the range of angles used is less than 360 degrees, as used in computed tomography. 